\title{
¿EPISTEMOLOGÍA BÍBLICA PARA LA INVESTIGACIÓN ADVENTISTA? UNA PROPUESTA DE TRABAJO
}

\section{Biblical Epistemology for Adventist Scholarship?}

A Working proposal

\section{Fernando Canale}

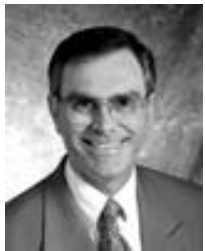

Doctor en Teología (Andrews University, Michigan, EE.UU.) y licenciado en Filosofía (Universidad Católica de Santa Fe, Argentina). Ex profesor de teología y de filosofía en el Colegio Adventista del Plata. Investigador y Profesor de Teología Sistemática en el Programa Doctoral de Teología de la Universidad Andrews. 


\section{Resumen}

Desde la creación de las primeras universidades adventistas a inicios de la segunda mitad del siglo veinte, la Iglesia Adventista del Séptimo Día ha participado en la investigación científica en varias disciplinas académicas seculares y teológicas que involucran el uso de metodología y razón humana. Debido a que normalmente, los investigadores seleccionan y usan metodologías basándose en el actual consenso de sus disciplinas académicas, y asumimos que eruditos adventistas hacen lo mismo. Rara vez los científicos se dan tiempo de analizar, evaluar y criticar las herramientas intelectuales que usan. Este estudio aborda la necesidad de implementar una epistemología bíblica para desarrollar investigaciones con perfil adventista.

Palabras claves: Epistemología, presuposiciones, investigación, metodología.

\section{Abstract}

Since the creation of the first Adventist Universities early in the second half of the twentieth century, the Seventh-day Adventist church has engaged in scientific research in several secular and theological scholarly disciplines that involve the use of human reason and methodologies. Because, normally, researchers select and use methodologies based on the current consensus of their scholarly disciplines, we have to assume Adventist scholars do the same. Seldom do scientists take time to analyze, evaluate, and criticize the intellectual tools they use. This article deals with the necessity of implement a biblical epistemology for developing researches with an Adventist profile.

Keywords: Epistemology, presuppositions, research, methodology. 


\section{Introducción}

Desde la creación de las primeras universidades adventi tas a inicios de la segunda mitad del siglo veinte, la Iglesia Adventi ta del Sépti Día ha parti en la investi ación científi a en varias disciplinas académicas seculares y teológicas que involucran el uso de ciertas metodologías y la razón humana. Debido a que normalmente los investi adores seleccionan y usan metodologías basándose en el actual consenso de sus disciplinas académicas, asumimos que eruditos adventi tas hacen lo mismo. Rara vez los científi os se dan ti de analizar, evaluar y criti ar las herramientas intelectuales que usan. Tanto como tengo conocimiento la instrucción adventi ta ha llevado a cabo la investi ación científi a mientras constantemente dejaba de lado la investi ación epistemológica y las conclusiones. ${ }^{1}$

Epistemología es la disciplina filosófi a que estudia las herramientas intelectuales con el fi de determinar su naturaleza, límites y confi cuando dan conclusiones y se desarrolla la enseñanza de cada disciplina académica. Eventualmente, la comunidad científi a adventi ta debería aclarar su posición respecto a la epistemología. ¿El dejar de lado conti te a la epistemología es aceptable para científi os y teólogos? ¿La instrucción adventi ta necesita involucrarse en el pensamiento epistemológico? Si razón y método no afecta el resultado de la investigación y enseñanza. El adventi probablemente podría conti sin preocuparse por la epistemología. Sin embargo, si lo hace, quedaríamos involucrados inmediatamente a causa de la unidad y misión de la iglesia. La ausencia de una epistemología comparti produce divisiones académicas (científi as y teológicas) y promueve puntos de vista incompati s con la misión de la iglesia.

Este artí ti doble propósito: Primero, presentaré al lector conceptos epistemológicos básicos que podrían ayudarlo a responder esta incógnita. En segundo lugar, argumentaré que la investi ación adventi ta no solo necesita parti en estudios epistemológicos, sino también debería desarrollar una epistemología bíblica como un marco general de la hermenéuti a para la investi ación disciplinaria e interdisciplinaria en universidades adventi tas. La aplicación intencional de la epistemología bíblica a todas las disciplinas académicas es la base intelectual necesaria para la unidad intelectual, para el surgimiento del proyecto universitario adventi ta y, sobre todo, para el avance de la misión de la iglesia a través de la comunidad científi a. 


\section{¿Qué temas estudia la epistemología?}

La epistemología es una disciplina filosófica que estudia la acción humana del conocimiento cuando sabemos que somos conscientes de los objetos o ideas. Por ejemplo, sabemos que estamos apreciando los contenidos de un libro, un auto, una persona, un verso bíblico y así sucesivamente. La medicina estudia al ser humano. La geografía estudia las características físicas de la tierra. La biología estudia elementos vivientes, etc. En un alto nivel de abstracción, la epistemología vuelve la acción de conocimiento en sí misma. La epistemología estudia no lo que sabemos (objeto de conocimiento), sino cómo llegamos a saberlo (la acción racional que genera el conocimiento).

La epistemología se enfoca en entender la acción del saber científico. La palabra "epistemología es un compuesto del griego "episteme" ( episteme, conocimiento), y "logos" (logoi, palabra, materia, estudio), eso significa el estudio del conocimiento científico en contraposición al conocimiento del día a día de la marcada opinión de platón. (doxa, gloria, apariencia, opinión). ${ }^{2}$

En tiempos clásicos, el pensar en ciencia y razón humana empezó como una Teoría del Conocimiento, una subdivisión de la antropología ontológica que trata con el origen, condiciones, esencia, límites y verdad de la razón humana. Trayendo el estudio del conocimiento y las ciencias (Matemáticas, Física y Metafísica) juntos, hemos de dar crédito a Immanuel Kant con el origen de la epistemología moderna como disciplina filosófica independiente. Hoy, la epistemología estudia el conocimiento y su rol en las ciencias. La filosofía de la ciencia es un capítulo en epistemología. Aquí es donde la epistemología discute el papel que desempeña la razón en el método científico en general y en el método especifico de cada disciplina en ciencia moderna.

A medida que empezamos a pensar en temas epistemológicos, muchas preguntas vendrán a nuestra mente. ${ }^{3}$ ¿Hay diferentes teorías que hablan de conocimiento? ¿Puede el razonamiento humano generar conocimiento que sea acertado y verdadero? ¿Cómo distinguimos entre opinión personal y conocimiento científico? ¿Qué relación se da entre el conocedor (sujeto) y el conocimiento (objeto)? ¿Cuáles son los límites del conocimiento humano? ¿Qué fundamentos hallamos en las Sagradas Escrituras que nos ayuden a desarrollar una epistemología para la instrucción adventista? ¿Cómo es que la razón y la revelación interactúa en el proceso cognitivo? ¿En qué forma nuestra propia cosmovisión, tradición y contexto social condicionan nuestro conocimiento? ¿Cómo la epistemología bíblica ayuda a los adventistas a evaluar hipótesis y teorías en disciplinas científicas y teológicas? ¿Cuál es la fun- 
ción del Espíritu Santo con respecto al conocimiento humano? ¿Cuáles son las implicaciones prácticas de la epistemología para un creyente adventista? No responderé todas estas preguntas en este artículo pues mi doble propósito fue establecido con anterioridad. Sin embargo, los he adjuntado para incitar la mente del lector y ayudar a involucrarse en el pensamiento epistemológico.

\section{La estructura básica de la hermenéutica}

Necesitamos empezar en el inicio. En epistemología, el comienzo es el generar conocimiento. ¿Cómo los seres humanos generan conocimiento ${ }^{4}$ Todo el conocimiento se origina de la relación entre sujeto-objeto, lo cual reacciona como la unidad fundamental cognitiva. El conocimiento, luego, toma lugar cuando un sujeto cognitivo (ser humano) y un objeto cognitivo (lo que sea que aparezca en la conciencia intencional de los seres humanos) vienen a tener contacto uno con el otro (ver ilustración 1, abajo).

Epistemología asume la actividad de un sujeto y su relación con un objeto.

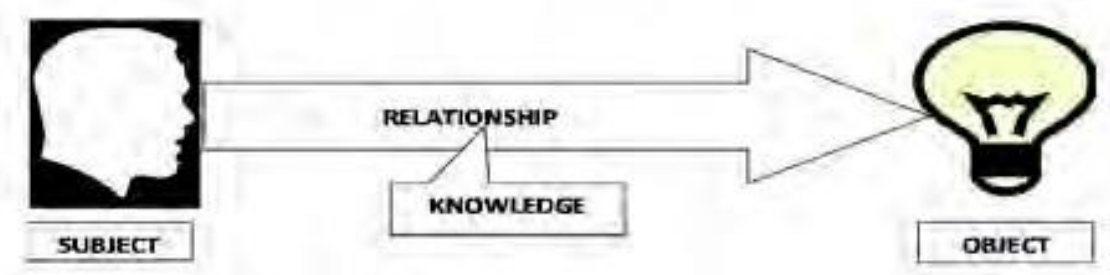

Ilustración 1: Las partes básicas de un evento cognitivo

El sujeto cognitivo (cerebro pensante) atrapa un objeto cognitivo. El objeto es cualquier cosa que podamos pensar o soñar. En consecuencia, el objeto puede ser ambos: intra y extra mental. Todo esto es un hecho más allá de la interpretación, aun la forma en que cada sujeto y objeto contribuyen a la creación de conocimiento, el cual ha sido interpretado de diversas maneras.

Filósofos clásicos y modernos creen que el conocimiento fue originado en su totalidad del objeto. Desde este punto de vista, el sujeto cognitivo, de forma pasiva, recibe el contenido del conocimiento por el objeto. ${ }^{5}$ Con esta creencia nuestra idea de conocimiento "objetivo" se mantiene. Para 
calificar al conocimiento como "objetivo" significa que éste debe de originarse en su totalidad del objeto, sin ninguna contribución del sujeto que podría distorsionar su "objetividad". Contribuciones del sujeto están personalmente distorsionadas y los prejuicios científicos deberían evadirse en sus creaciones y conclusiones. Por más de tres siglos, el pensamiento epistemológico nos ha llevado a darnos cuenta que el sujeto cognitivo también contribuye a la creación de nuestro conocimiento científico "objetivo". Durante los últimos diez años del siglo veinte, pensadores postmodernos ampliamente aceptaron esta convicción. La epistemología paso a ser hermenéutica.

\section{Epistemología y hermenéutica}

Por siglos, la hermenéutica fue una rama del conocimiento que lidiaba con la interpretación de textos, especialmente de la Biblia o los textos literarios y jurídicos. Por lo tanto, hasta el siglo veinte, la hermenéutica pugnó con la interpretación de textos, y la epistemología con la interpretación de esencia. A finales del siglo pasado, los límites entre la epistemología y la hermenéutica se borraron. De un lado, los científicos se dieron cuenta que sus conclusiones no solo tenían que ver con información esencial sino también con las conclusiones humanamente dadas por la investigación. De otro lado, los filósofos volvieron su atención a la interpretación como un fenómeno cognitivo general no limitado a textos sino a toda cognición humana. En fin, interpretación se volvió un sinónimo de conocimiento.

Saber es interpretar. ${ }^{6}$ Interpretar significa que el sujeto cognitivo contribuye a la creación de nuestro conocimiento de esencia y formas humanamente creadas (textos, artefactos, idioma, etc....). Hermenéutica y epistemología, entonces, están muy relacionadas. Debido a la hermenéutica de los textos descubiertos antes que las contribuciones del sujeto a la creación del conocimiento involucraran "principios de interpretación", uno puede argumentar que la epistemología postmoderna deriva de la hermenéutica.

\section{Presuposiciones como condiciones del conocimiento}

El reconocer que el sujeto cognitivo contribuye a la creación de conocimiento científico y teológico no pide dejar de lado a las contribuciones del objeto, y tampoco implica un relativismo. En vez de eso, la epistemología hermenéutica alienta a la libre y completa contribución del objeto en el proceso de la formación del conocimiento. 
Debido a que las contribuciones del sujeto se encuentran en el tema antes de que el acto de la interpretación se lleve a cabo, les llamamos "presuposiciones". En consecuencia, las presuposiciones son ideas tácitamente adoptadas por el sujeto antes de que éste lleve a cabo un acto de conocimiento. Son necesarios para dar sentido al objeto cognitivo. El conocimiento resulta de la unión complementaria de la presuposición y contenidos objetivos. Tal vez la mejor forma de entender el rol de las presuposiciones es relacionarlas a una idea más familiar de contexto.

Por "contexto", nos referimos a las partes de un discurso o escrito que de inmediato precede y sigue a una palabra o pasaje el cual nos ayuda a aclarar y determinar su significado. Presuposiciones son ideas o información tácitamente asumida antes de interpretar naturaleza o forma humanas.

¿De dónde vienen las presuposiciones? Se originan de previas experiencias de vida. Así, la suma total de nuestras presuposiciones incluye las experiencias de toda nuestra vida hasta el presente almacenado en nuestra memoria así como en un disco duro. Sin embargo, no todas las suposiciones desempeñan el mismo papel o trabajo simultáneamente. En cambio, como nuestro conocimiento intencional se enfoca en un objeto cognitivo, nosotros automáticamente y no intencionalmente seleccionamos de nuestra memoria las ideas e información que se relaciona directamente al objeto de nuestra atención al cual necesitamos como contexto para entender.

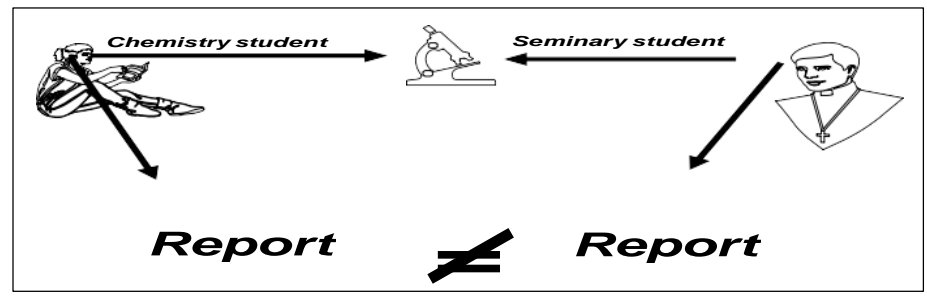

Ilustración 2: Analogía del microscopio

La ilustración 2 podría ayudarnos a ver cómo se da este proceso. Un profesor de biología prepara una muestra de tejido para examinar en el microscopio. Luego él llama a un estudiante avanzado de química y a un estudiante avanzado de teología para observar. Después de que estudiaron la muestra cuidadosamente, el profesor pide que redacten un reporte. No es de extrañar, que los reportes sean muy diferentes. La razón de ser de las presuposiciones que cada uno trajo por percepción del mismo objeto cognitivo. 
Con esto en mente, podemos entender el significado técnico de la palabra "condición" en epistemología. Este lenguaje encontró un rol permanente en epistemología desde que Kant publicó su crítica de Razón Pura (1781). Las presuposiciones son condiciones de nuestro entendimiento de los objetos (textos, eventos, imaginación, etc....) porque éstas contribuyen tácitamente a nuestro conocimiento sobre ellas. Por lo tanto, cuando decimos que una idea condiciona un panoramas o que un panorama está condicionado, los epistemólogos se refieren a la suposición tácita que el sujeto cognitivo aplica al entendimiento de cualquier objeto o evento.

Podemos dar una conclusión parcial, las presuposiciones condicionan todo el conocimiento porque cada acto de conocimiento forma parte de un gran discurso de vida e historia (personal y social). Siendo así, las presuposiciones tácitas condicionan nuestro entendimiento de las santas escrituras y doctrinas. Las presuposiciones inclusive condicionan nuestro entendimiento de epistemología y metodología científica. Permítanos ver como el análisis básico fenomenológico del acto de conocimiento que describimos arriba nos ayuda a descubrir las presuposiciones macro-hermenéuticas que condicionan la tarea del teólogo cristiano.

\section{Ontología condiciona a la epistemología}

La acción básica de la cual el conocimiento se origina está en la relación entre sujeto-objeto. Una mirada más atenta revela que la epistemología trata de entender la forma en la cual el sujeto cognitivo y el objeto cognitivo se relacionan. La epistemología estudia la esencia y los límites de la relación cognitiva y su extensión en la metodología científica. Sin embargo, el generar conocimiento incluye un entendimiento previo de la realidad de ambos: el sujeto y objeto. Es evidente que, a menos que el sujeto y el objeto sean de alguna manera "reales", no puede haber relación entre sujeto-objeto, conocimiento o epistemología. Más importante aún, la comprensión que asumimos de la realidad del sujeto y objeto influencia radicalmente la forma en la que entendemos. Esto es especialmente verdad en el pensamiento científico y teológico.

Supuestos tácitos de la realidad deben ser muy específicos a ideas extremadamente generales. A causa de que las ideas generales son el contexto implícito de ideas especificas estas son la condición de su entender. Mientras la filosofía se enfoca en ideas generales, las ciencias "duras" y "blandas" se enfocan en ideas que son más específicas. Por esta razón, la filosofía 
estudia la realidad supuesta que cada ciencia empírica estudia. Ya que, en filosofía, ontología es una disciplina que estudia las características generales y naturales de lo que es real, podemos decir que ontología condiciona a la epistemología y que ambos condicionan nuestro entendimiento científico de todas las ciencias, incluyendo la interpretación bíblica y teología cristiana.

Ontología, incluye ontologías regional y general. La ontología general estudia el asunto del ser (el signifi ado de la palabra "es"), y enti en general (categorías que todas las enti s comparten). Ontología regional incluye a la ontología antropológica, cosmología y metafí a. La antropología estudia las característi as generales de las enti humanas. La cosmología o cosmovisión estudia el origen, funciones y esencia del universo fí o. La metafí a estudia la armonía de todas las cosas, incluyendo a todos los sujetos cogniti os.

Ontología, antropología, cosmología y metafísica están reflejadas en asuntos generales que asumimos tácitamente en la formación de conocimiento científico y teológico. Los filósofos interpretan estos asuntos filosóficos de varias maneras a causa de que el pensamiento filosófico emerge del mismo suceso de sujeto-objeto donde todo conocimiento se origina. ${ }^{7}$

\section{La epistemología condiciona a la ciencia y a la teología}

La mayoría de científicos y teólogos vive bajo la ilusión epistemológica de que sus conclusiones y enseñanzas son "objetivas". Por "objetivas", normalmente quieren decir "esperar a todo ser racional". Después de ser extremadamente cuidadoso y meticuloso al tratar con toda la información y evidencia relacionada a sus temas de estudio, teólogos y científicos esperan que toda persona racional esté de acuerdo con sus conclusiones. Asumen que sus conclusiones son absolutas, quiere decir que tienen valor universal para todo ser racional. De hecho, tácitamente asumen los puntos de vista epistemológicos clásicos y modernos.

Sin embargo, aun la concepción moderna de la ciencia pide universalidad basada solamente en una empírica y permanente verificación. Por otra parte, ni siquiera la epistemología moderna se refiere a los resultados de la ciencia como algo absoluto, sino como algo hipotético. Karl Popper fue uno de los más grandes filósofos de ciencia en el siglo veinte. ${ }^{8}$ Siendo especialista en el método científico, llegó a la conclusión de la certeza del conocimiento científico mediante el uso de la analogía de un edificio y sus bases. "La base empírica de la ciencia objetiva no tiene nada 'absoluto' de esto. La ciencia no descansa sobre roca sólida. La audaz estructura de sus teorías se levanta, 
por así decirlo, por encima de un pantano. Es como un edifi erguido sobre pilares (en prueba). Los pilares son hundidos en el pantano, pero no dejados sobre alguna base natural o dada; y si detenemos los pilares para que no sigan hundiéndose, no es a causa de haber alcanzado ti a fi . Simplemente nos detenemos cuando nos senti sati fechos de que los pilares se encuentren lo sufi ntemente fi para llevar sobre ellos una estructura, al menos por el momento. ${ }^{9}$

En mi opinión, los teólogos y científicos adventistas asumen implícitamente ideas epistemológicas clásicas y modernas. La idea de que la verdad racional es universal y absoluta parece ajustarse a la convicción de grandes teólogos y científicos adventistas. La mayoría ve la posmodernidad como una amenaza a su creencia básica de que la verdad es absoluta. ${ }^{10}$ Si no existieran más verdades absolutas, los adventistas no podrían decir que su verdad y mensaje son absolutos. En consecuencia, no podríamos decir más que somos la iglesia remanente con el mensaje verdadero.

No obstante, pocos han notado que el relativismo postmoderno es positivo para la iglesia adventista. Solo necesitamos darnos cuenta que la postmodernidad nos muestra que las conclusiones racionales y científicas no son absolutas. En resumen, la razón no tiene lo que se necesita para producir verdades universales y absolutas. Aquellos que suponen que el relativismo postmoderno obliga a los adventistas a un relativismo teológico deberían recordar que la verdad absoluta del mensaje del tercer ángel no se ha mantenido en el poder de la razón, sino de la revelación bíblica. ${ }^{11}$

La epistemología moderna tácitamente compartida por profesores universitarios adventistas crea un diálogo constructivo entre la ciencia y la difícil teología, particularmente en el adventismo. Inconscientemente incorporaron ideas epistemológicas modernas simplemente aprendiendo y haciendo investigación en sus disciplinas. Por lo tanto, la tendencia a juzgar las Sagradas Escrituras desde la enseñanza de ciencias parece lógico para muchos científicos, aun teólogos, a pesar del consejo de Elena de White para juzgar a las ciencias desde las Sagradas Escrituras. Oculto y adoptado de forma acrítica, las enseñanzas epistemológicas modernas están adaptándose a la mente adventista, la investigación académica en las universidades adventistas, e incluso a la teología y práctica adventista. ${ }^{12}$

Después de todo, muchos sostienen, que Dios es el autor de toda verdad, tanto en la Escritura como en la naturaleza. Ellos afirman que éste es un enunciado verdadero, descuidando el rol de acondicionamiento de la epistemología en el origen del conocimiento científico y teológico. Además, fallan 


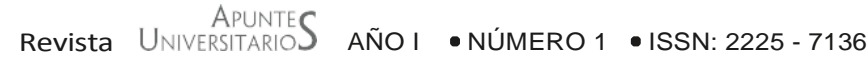

al notar que el conocimiento científico y teológico no son un hecho absoluto, sino interpretaciones.

\section{Epistemología en la teología cristiana}

La teología cristiana está situada sobre una innumerable fuente de revelación. Esto significa que los teólogos obtienen sus datos de las Sagradas Escrituras, tradiciones de la iglesia, enseñanzas filosóficas y científicas (ontología y epistemología) y experiencia, todo considerado como vehículo de revelación divina. Este punto de vista se desarrolló a comienzos de la historia del cristianismo y es la base del sistema teológico católico romano, culto y administración. Los reformadores protestantes en realidad nunca desafiaron esta base. En la creación de la teología cristiana, la reforma rogó por "la sola escritura" (doctrina) en realidad nunca sustituyó los múltiples recursos de los fundamentos de revelación para información teológica; solo lo modificó en temas específicos. Hoy, las múltiples fuentes del principio de revelación, mejor conocidas como el Cuadrilátero Wesleyano, es ampliamente aceptado por las principales denominaciones protestantes y también por los evangélicos conservadores.

Por supuesto, esto se volvió necesario a causa de que las ideas filosóficas griegas referidas a ontología y epistemología reemplazarán las enseñanzas del antiguo testamento como supuestos para entender el nuevo testamento. Desde entonces los teólogos cristianos clásicos (conservadores) aceptaron, de una manera dogmática, las enseñanzas fundamentales ontológicas y epistemológicas creadas por filósofos del paganismo griego, notables como: Parménides, Platón y Aristóteles. Teólogos cristianos modernos (liberales) rechazaron la filosofía griega y la reemplazaron con las ontologías y epistemologías científicas (procedimiento de ontologías y epistemologías). Para ser justo con los teólogos evangélicos conservadores, tengo que decir que la mayoría de ellos en realidad cree que sus doctrinas son enteramente bíblicas sin influencia alguna de la epistemología u ontología humana. Ellos incondicionalmente confunden su ignorancia en temas ontológicos y epistemológicos con la ausencia de presuposiciones e información bíblica en su sistema de creencias. Mientras más bíblico sea, menos ven las enseñanzas ontológicas y epistemológicas que condicionan su pensar.

Teología creativa con solidez bíblica es rara entre los adventistas. Siguiendo una tradición que se puede rastrear al menos hasta 1888, los adventistas solían sentirse cómodos adoptando su teología de los teólogos protes- 
tantes clásicos y modernos. En consecuencia, la mayoría de nosotros también somos inconscientes del papel que la epistemología y ontología desempeñan en nuestro propio pensar teológico adventista. Esto explica la existencia de adventistas modernos, ${ }^{13}$ y el total "protestantismo" del adventismo que se ha dado lugar en los últimos cincuenta años.

\section{¿Una epistemología adventista?}

El saber es interpretar. Para interpretar necesitamos presuposiciones. Para hacer ciencia y teología necesitamos presuposiciones epistemológicas. Normalmente, adoptamos presuposiciones epistemológicas inconscientemente a través de los procesos de aprendizaje e investigación. En consecuencia, la mayoría de teólogos y científicos adventistas no tratan con cuestiones epistemológicas y el papel condicionante en sus disciplinas. Este proceso es rápidamente secularizante ante el pensar adventista, vida, ministerio, instituciones y misión. Además, en el nivel académico hay una fatídica desconexión entre teología y disciplinas. Como las disciplinas universitarias se desarrollan en desconexión con las Escrituras y la teología, puntos de vista opuestos surgen entre los profesores, arduos temas que se debaten y divisiones en la comunidad de fe que ha sido transmitida, sin resolver, de generación en generación.

La pregunta es, ¿ipueden los investigadores adventistas revertir este proceso? Deberían ponerse al corriente del rol condicionante de la epistemología en cada disciplina. Aun así, esto solo los ayudará a entender la razón intelectual de sus divisiones teológicas y desconexiones interdisciplinarias. Si le preguntamos a Elena de White cómo hacerlo, ella nos diría que comparemos las afirmaciones científicas con lo que la Biblia dice del hecho de la naturaleza que busca una armonía entre las verdades de la naturaleza y la revelación. ${ }^{14}$ Esto es lo que hemos estado haciendo por largo tiempo y causó los resultados negativos mencionados con anterioridad. Es en este ámbito, donde necesitamos encontrar una mejor forma para lidiar entre las Escrituras y la ciencia. Tal vez el principio básico de Elena de White el cual dice "la Biblia no está para ser puesta a prueba por las ideas de hombres de ciencia, pero la ciencia debe ser llevada a prueba ante la Norma Infalible" ${ }^{\prime 15}$, nos puede indicar el camino a seguir.

Su principio no es nuevo, no más que el uso del principio protestante de la sola escritura. Expresado en voz activa, el principio dice, "las ideas de hombres de ciencia no deben poner a prueba a la Biblia". A pesar de eso, 


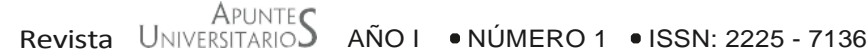

¿Cuál es el signifi ado de la expresión "ideas de hombres de ciencia”? La preposición "de" que usualmente signifi a "desde", indica origen y posesión, a veces también signifi a "acerca." ${ }^{16}$ Así, puede tomar el signifi ado de "ideas de hombres de ciencia", esto es, ideas científi as originadas de una acti científi a. Además, podría signifi ar "ideas de hombres acerca de ciencia", y eso es ideas acerca de la naturaleza de la ciencia. Estoy seguro de que Elena G. de White no tenía intención de decir esto últi No obstante, el últi signifi ado no contradice al primero pero lo generaliza. Podría decirse, entonces, que una amplia lectura del principio de Elena de White no solo previene a las ideas científi as específi as de "poner a prueba" a las Escrituras, pero también dice que no podemos usar puntos de vista humanos con la naturaleza de la ciencia como modelo para juzgar a las Escrituras. ${ }^{17} \mathrm{La}$ segunda parte de la afi de Elena de White se encuentra en voz activa," la Norma Infalible (Escrituras) deben poner a prueba (juzgar) a la ciencia". Implícitamente y probablemente sin saberlo, Elena de White impulsó el concepto positi o de que la Escritura debería poner a prueba a las teorías epistemológicas. Una epistemología adventi ta, debe aplicar a la ciencia la sola (única) y la prima (primer) principio de Escritura. En pocas palabras, los principios macro epistemológicos deberían venir solo de las Escrituras, una vez identifi adas, deberían ser aplicadas a toda acti científi a. (Primero las escrituras)

\section{Las Escrituras y la epistemología}

Una epistemología adventista debe ser una epistemología bíblica. Al ojo casual, una epistemología bíblica parece imposible porque, como se explicó antes, la epistemología es una disciplina filosófica que depende de la ontología, otra disciplina filosófica. Además, la Escritura no contiene enseñanzas ontológicas o epistemológicas que podamos acceder a través de análisis exegético. Aunque la Biblia no apunta a las cuestiones epistemológicas, asume su existencia y operación. La Escritura es un hecho o producto de la razón humana. Sin acción racional no habría Escritura o Revelación. La Epistemología, entonces, es la condición de la revelación bíblica.

Sin embargo ante un ojo entrenado, una epistemología bíblica es posible como interpretación y construcción. Como señalé anteriormente, Epistemología es la interpretación de la relación sujeto-objeto. A través de la historia, filósofos produjeron una variedad de puntos de vista epistemológicos. Un cuidadoso estudio de la historia de la filosofía nos revela que cambios 
en teorías epistemológicas produjeron cambios en la enseñanza ontológica. Esto confirma el análisis fenomenológico que muestra su dependencia de las teorías ontológicas (ver pág. 4). Resumiendo, debido a la variedad de epistemólogos ontológicos se han creado muchas interpretaciones de la razón. Puesto que la razón como generador de la relación sujeto-objeto del conocimiento y lenguaje humano pertenece al mundo de naturaleza (esencia) la única condición para la existencia de una epistemología bíblica es la existencia de la ontología bíblica.

Indiscutiblemente, la Escritura habla del ser en general (Éxodo 3:1415); Antropología, la naturaleza y acciones del ser humano; Cosmología, el origen y naturaleza del universo y vida sobre la tierra; y, Metafísica, la restauración de la armonía entre el único (Dios) y lo demás (criaturas). Sin embargo, a causa de la creencia tradicional de que las interpretaciones de epistemología son compatibles con la Escritura, teólogos cristianos incluyendo investigadores adventistas nunca hicieron uso de esas ideas para desarrollar una epistemología u ontología bíblica.

Desde el primer trabajo de Parménides, Platón, y Aristóteles en Ontología, teólogos y filósofos entendieron la "realidad definitiva" como algo sin tiempo ni espacio porque este no pasa, termina o desaparece. Las cosas temporales y espaciales son reales solo en un sentido ilusorio porque estas pasan. Desde este punto de vista ontológico teológicos cristianos definieron al ser de Dios como incompatible con el tiempo y espacio, el "alma" humana como una sustancia inmortal (entidad), y al cielo como si en él no existiera espacio ni tiempo. La teología cristiana modela su teología y epistemología asumiendo que estos puntos de vista son verdades absolutas y universales. Hasta ahora, un examen preliminar de las Escrituras señala que la ontología bíblica se aparta radicalmente de la ontología tradicional en la cual la teología cristiana clásica se construye. La diferencia básica aparece en el nivel más elemental de la realidad. ${ }^{18}$ Autores bíblicos no conciben a la realidad definitiva como no poseedora de tiempo o espacio pero sí la conciben como histórica, temporal y espacial. La realidad humana no es un alma eterna pero sí es una entidad humana histórica y espacial. La cosmología no es una jerarquía de especies firmes (pensamiento) pero sí es un proceso complejo temporal y espacial de entidades naturales y espirituales creadas por Dios en el tiempo; en nuestro planeta, Dios creó vida en seis días literales y terrestres. En consecuencia, al entender la realidad como un todo, la metafísica se transforma en una meta narrativa adventista completa (todo incluido) identificado como la Gran Controversia. 
La existencia de las ideas ontológicas y epistemológicas en las Escrituras hace posible una epistemología adventista. La tarea es inmensa. Tenemos que empezar desde cero. El método a seguir mientras desarrollamos las enseñanzas ontológicas y epistemológicas de las Escrituras no será solo descriptivo como en la interpretación de un texto (exégesis), sino que también será constructivo, como en la teología sistemática. La meta será el entendimiento bíblico de la relación sujeto-objeto; la interpretación de metodologías científicas y teológicas; la estructura y método disciplinario de todas las ciencias en la universidad. Esto proveerá de la base intelectual necesaria en la cual la investigación adventista y el pensamiento intelectual deberían desarrollarse.

\section{Epistemologías generales y regionales}

¿Cómo debería el entendimiento epistemológico bíblico relacionarse con la investigación académica y la enseñanza que se da en las universidades adventistas? Para responder esta pregunta necesitamos distinguir entre el campo regional y general de estudios epistemológicos. La epistemología general estudia en su totalidad la naturaleza y condiciones del acontecer del conocimiento entre sujeto-objeto. La epistemología regional, estudia el objetivo general, métodos y condiciones hermenéuticas del trabajo en cada disciplina académica. Usualmente los filósofos crean interpretaciones de epistemología general, y científicos familiarizados con la historia de ciencia y filosofía crean epistemología regional.

Desde que todas las ciencias asumen el mismo manejo general cognitivo, implícitamente o explícitamente asumen una interpretación de epistemología general. Además, desde que la epistemología general adquiere las interpretaciones de asuntos ontológicos en su totalidad, los estudios epistemológicos regionales de cada ciencia particular elaboran su propio método y programa de investigación explícita o implícita asumiendo algunos puntos de vista en ellos como el ser, la antropología, la cosmología y metafísica (la unidad y la multitud).

\section{Escogiendo entre las visiones epistemológicas}

Debido a que conocimiento es interpretación, los filósofos han interpretado estos asuntos de varias formas. Por lo tanto, todo científico y teólogo debería tomar conciencia de las ideas que asumen y las alternativas dispo- 
nibles. Después de una investigación y reflexión debida sobre estos temas, teólogos y científicos deberían explícitamente escoger la interpretación de asuntos ontológicos y epistemológicos implicados en sus metodologías.

Sin embargo, como se mencionó con anterioridad, la mayoría de teólogos y científicos ignoran los conceptos epistemológicos y ontológicos que recibieron mediante una educación formal o informal. Aun así, las ideas tácitas y no criticadas que recibimos al pertenecer a una comunidad juegan un papel protagónico en nuestro pensar, investigación y enseñanza. El análisis epistemológico puede ayudarnos a analizar y extraer las presuposiciones que heredamos de la tradición; sin embargo, esto no puede ayudarnos a decidir por nuestro propio pensamiento e investigación. En la fundación del pensamiento científico descansa una fatal decisión que podemos hacer sólo por fe. ¿Qué escuela (o corriente) del pensamiento debería seguir un adventista? Para teólogos y científicos adventistas, la elección es muy compleja. Además de las varias tradiciones ontológicas y epistemológicas, ellos podrían escoger seguir la visión ontológica y epistemológica bíblica. Desde que la elección del fundamento científico se encuentra en la fe, el escoger seguir los puntos de vista ontológicos y epistemológicos bíblicos es tan racional como escoger seguir la sabiduría convencional de la comunidad científica.

Puesto que nadie ha desarrollado la visión bíblica sobre temas epistemológicos y ontológicos de manera intelectual, uno se pregunta cómo es que los teólogos y científicos adventistas pudieron evitar adoptar ideas epistemológicas convencionales. Sin duda, adoptar una epistemología no bíblica transgrede la primera creencia fundamental y desecha el principio de la sola Escritura sobre el cual el adventismo se sostiene. De este modo, el mundo de la instrucción adventista necesitara escoger una base epistemológica bíblica, desarrollarla para responder las preguntas dadas por las epistemologías generales y regionales, y usarla en su enseñanza e investigación.

\section{Las ciencias y la teología en el adventismo}

¿Cómo deberían relacionarse la teología y las ciencias en la Universidad Adventista? Actualmente, científicos y teólogos adventistas elaboran sus "supuestos epistemológicos tácitos" por ausencia de un consenso de instrucción actual. A pesar de todo, si todas las disciplinas científicas y teológicas en la universidad adventista conscientemente eligen usar principios macro-hermenéuticos que emanen de la epistemología bíblica, una fuerte base para un diálogo constructivo interdisciplinario entre todas las ciencias 
y teología transformaría la universidad adventista en un líder de instrucción mundial y en una herramienta afilada para la unidad y misión de la iglesia.

¿Cómo podría funcionar este proyecto? Primero, requiere que el adventismo desarrolle las nociones generales de la erudición bíblica ontológica y epistemológica. ${ }^{19}$ Segundo, como la adopción de todas las epistemologías implica una elección de fe, para el adventismo significa fe en el principio de la sola, tota, and prima Scriptura. Cuando los principios generales de la epistemología bíblica sean elaborados con instrucción (erudición), todas las disciplinas teológicas y científicas usarán estos principios mientras guían prepresuposiciones hermenéuticas a determinar sus propias epistemologías regionales, específicamente, su metodología y objetivo disciplinario.

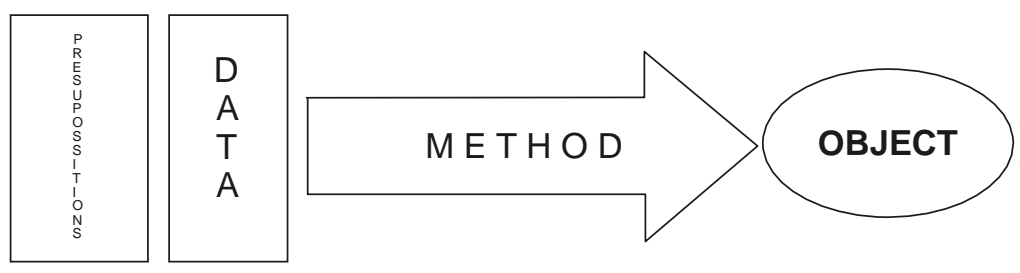

llustración 3: La estructura del método

El análisis epistemológico revela que, considerado en forma general, el método es una actividad que adopta tres principios que condicionan su forma, proceder, naturaleza, limitaciones y resultados (ver ilustración 3). Éstas son las condiciones materiales, teológicas y hermenéuticas. La condición material se refiere a la elección de información. La condición teológica involucra la elección de la meta o el propósito del método que busque alcanzar. Las condiciones hermenéuticas incluyen las condiciones generales de fe que los procedimientos requieran para interpretar la información y alcanzar su objetivo. La erudición que lidera actualmente en ciencias y teología hace sus supuestos macro-hermenéuticos a partir de la interpretación humana de las condiciones ontológicas de la epistemología (el único-Dios-, el mundo, y la naturaleza humana).

Como ejemplo, las ciencias empíricas entienden que "el único" es parte de la naturaleza (¿su energía interior?), al mundo como el universo envolvente, y al espíritu humano como material (no existe el alma humana). Esto contrasta con las condiciones ontológicas de la epistemología bíblica. 


\section{Fernando Canale}

Como una descripción introductoria muy simplificada, podemos decir que "el único" es el Dios bíblico (en contraste con el Dios del teísmo y el deísmo), "los muchos" son el universo creado, la vida sobre la tierra creada en siete días literales; la Gran Controversia entre Cristo y Satanás, y la naturaleza humana encarnada en el hombre integral. ${ }^{20}$

¿Cómo la epistemología humana influye en las ciencias y en su diálogo con la teología? Empezando desde la esquina superior izquierda en la ilustración 4, vemos que los principios epistemológicos predeterminados de profesores adventistas y teólogos captados de sus respectivas comunidades científicas se originan a partir de la interpretación humana del mundo natural. Actualmente, el naturalismo (Dios no está en el cuadro) y la cosmología evolutiva se han tornado los principios macro-hermenéuticos. A causa de su totalidad (todo incluido) toda disciplina teológica y científica los asume. A razón de que las ciencias y teología asumen el mismo punto de vista de los principios epistemológicos generales, un trabajo constructivo interdisciplinario puede ejecutarse. Por lo tanto, en la esquina izquierda, en la parte inferior de la ilustración 4 vemos a la teología recibiendo sus principios epistemológicos de la filosofía humana. En la esquina inferior izquierda, vemos los mismos principios aplicados a las ciencias. Católicos romanos, protestantes y denominaciones evangélicas hacen teología y de esta forma se relacionan con la ciencia.

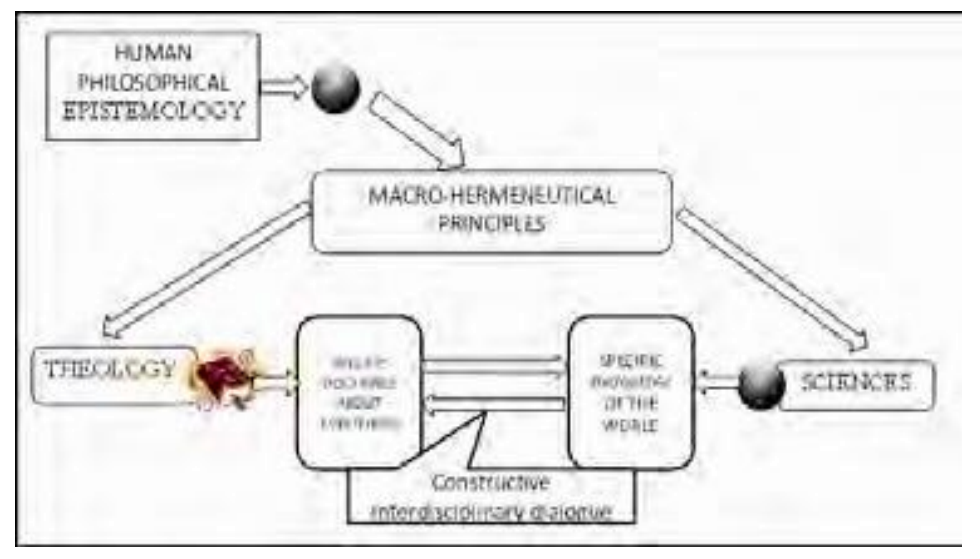

Ilustración 4: Epistemología científica y consenso de ciencias 
El problema de este método es el rechazo total del principio de la sola, tota, y prima Scriptura. Eruditos adventistas que tratan de relacionar sus creencias bíblicas con las tácitas presuposiciones epistemológicas humanas pronto descubren que no encajan en el consenso científico actual. Específicamente, sus creencias teológicas y científicas se contradicen entre ellas. La tendencia normal es tomar a ambos por su valor nominal como verdad, y armonizarlos. Esto debido a que el desarrollo de la base epistemológica de las ciencias y la tradición cristiana es mejor que la teología adventista, teólogos y científicos adventistas suelen adaptar sus creencias bíblicas a la enseñanza de la cultura y la ciencia. Este cambio intelectual ha tomado lugar durante los últimos cincuenta años y se ha intensificado desde el cambio de siglo.

En el adventismo, éste es el modus operandi del autodenominado "Adventismo Progresivo". Ellos interpretan la Escritura y construyen teología adventista guiados por principios epistemológicos creados por pensadores humanos quienes contemplan el mundo natural histórico. Biblia y teología se adaptaron a la cosmología evolutiva y cultura contemporánea. Si la iglesia no cuestiona esta tendencia, el adventismo adoptará el sistema protestante de teología y se unirá al movimiento ecuménico liderado por Roma. La iglesia puede revertir esta tendencia formulando y aplicando principios bíblicos epistemológicos sobre los cuales construir la universidad adventista.

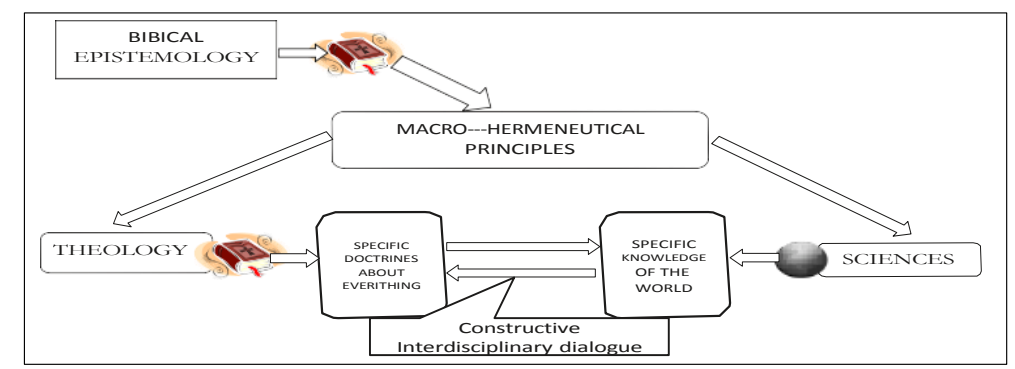

Ilustración 5: Epistemología bíblica y las ciencias 
La ilustración 5 nos ayuda a ver cómo es que la epistemología bíblica se convierte en la base intelectual para la universidad adventista. En la esquina superior izquierda vemos que la epistemología bíblica produce los principios macro-hermenéuticos que guían en la formación disciplinaria y metodologías de ambas disciplinas teológica y científica, Dios como revelado en las Escrituras reemplaza al naturalismo; la creación y la Gran Controversia reemplazan a la historia evolutiva, y el hombre histórico holístico reemplazan al alma eterna. Científicos adventistas se enfrentan a una elección. Ellos pueden continuar surfeando en el consenso epistemológico humano de sus respectivas comunidades académicas o cambiarlas por aceptar y aplicar los principios bíblicos hermenéuticos.

\section{Conclusión}

Oculto e inesperado, la amplia gama de ideas filosóficas acerca de la realidad (Dios, el mundo, los seres humanos y el conocimiento) condicionan la visión, conclusión y enseñanzas de todas las disciplinas científicas y teológicas. De forma intuitiva, los primeros adventistas estaban al tanto del papel de la filosofía hermenéutica.

Los adventistas conservadores piensan que tienen todo claro con respecto a la función hermenéutica de las ideas filosóficas evadiendo estudios filosóficos y solo enfocándose en los estudios de la Biblia. Aun así, Elena de White nos advirtió que "las tradiciones de los hombres, son como gérmenes flotantes que se adhieren a la verdad de Dios y los hombres las consideran como una parte de la verdad." ${ }^{21}$ Consecuentemente, debido a que un número creciente de adventistas siente libertad de copiar teologías y ministerios protestantes, interpretaciones filosóficas de los principios macro-hermenéuticos de la epistemología vinculados a su punto de vista teológico y prácticas ministeriales encuentran el modo de introducirse en la investigación (erudición) adventista, educación y la comunidad pastoral. Este proceso ha generado una versión moderna de teología adventista, creencia y misión designada como "Adventismo Progresivo".

Para romper la desintegración del pensamiento científico teológico adventista no solo necesitamos conservar el principio de la sola, tota y prima Scriptura, sino desarmar de forma crítica todas las tradiciones recibidas. Sin embargo, a causa de que científicos y teólogos necesiten usar numerosas ideas filosóficas para interpretar su información y formular sus enseñanzas, eruditos adventistas necesitan considerar seriamente la importancia de 


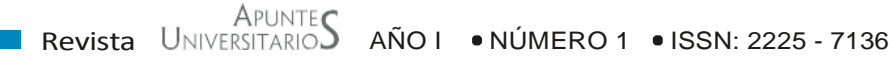

desarrollar principios ontológicos y epistemológicos que puedan basarse en las Escrituras, que trabajen en una epistemología general sobre la cual se desarrolle las epistemologías regionales de todas las disciplinas teológicas y científicas.

Fernando Canale Andrews University e-mail: canale@andrews.edu

Recibido: 15 de Septiembre de 2011

Aceptado: 30 de Septiembre de 2011 


\title{
Fernando Canale
}

\section{Notas}

\author{
${ }^{1}$ Estaré complacido al saber que mis asunciones tiene excepciones alrededor del mundo \\ 2 Platón, The Republic, 477, a-b \\ ${ }^{3}$ Las preguntas en este párrafo fueron formuladas por el Doctor Humberto Rasi (e-mail personal, \\ $1 / 10 / 2008)$.
}

${ }^{4}$ Técnicamente, éste es el asunto del origen del conocimiento. En tiempos modernos, racionalistas y empíricos discuten este punto nuevamente. Partiendo en Descartes, los racionalistas argumentan que el conocimiento científico empieza en el alma humana, en sus ideas "innatas" dadas por Dios. Los empíricos parten de Lock Y Hume, quienes argumentan que el conocimiento humano se origina de experiencias de percepción sensorial. Éstos últimos han llevado a lo que hoy conocemos como ciencia moderna. Esto ayuda a responder la pregunta que formulamos hace un momento: ¿hay distintas y variadas teorías de conocimiento? Sí, hay varias, el racionalismo y empirismo son dos de ellas.

${ }^{5}$ Éste es el caso de cuando nos fijamos en la relación de sujeto-objeto desde la perspectiva del contenido del conocimiento. Si nos fijamos en la misma relación desde la perspectiva de la aprensión del conocimiento, veremos que el sujeto es activo y el objeto pasivo. Que yo sepa, nadie pone en duda este punto.

${ }^{6}$ Para una introducción a este fenómeno lee Fernando Canale, Creation, Evolution, and Theology: The Role of Method in Theological Accommodation (Berrien Springs, MI: Andrews University Lithotech, 2005). Nota del editor: Existe una versión en español Fernando Canale. Creación, evolución y teología: Una introducción a los métodos científico y teológico (Entre Ríos, Argentina: Editorial Universidad Adventista del Plata, 2009).

${ }^{7}$ Esto nos trae a la existencia y la contribución de la "espontaneidad" del sujeto cognitivo. Cuando nos damos cuenta de que la libertad y el conocimiento coinciden en la "espontaneidad" del "sujeto cognitivo", alcanzamos la base máxima de la acción del conocimiento. La espontaneidad del sujeto implica la capacidad ilimitada del sujeto cognitivo de crear diversas interpretaciones del mismo objeto. La "espontaneidad" del sujeto brota de la conjunción del sentir del sujeto cognitivo, imaginación y libertad. En el rol de la imaginación y sentimientos en metafísica lea, por ejemplo, John Kekes, "'Feeling and Imagination in Metaphysics," Idealistic Studies 7, 1977: 76-93.

${ }^{8}$ Stephen Thorton, Stanford Encyclopedia of Philosophy (Stanford, CA: Sanford University, http: // plato.stanford.edu/entries/popper/, 2006): Karl Popper.

${ }^{9}$ Karl Popper, The Logic of Scientific Discovery (London: Hutchinson, 1968).

${ }^{10}$ Yo conozco pocas evaluaciones de postmodernidad, vea por ejemplo, Norman R. Gulley, "The Fall of Athens and the Challenge of Postmodernity", Journal of the Adventist Theological Society 
10, no. 1/2 (1999), Larry L. Lichtenwalter, "Generation Angst and the Ethical Paradox of Postmodernity", Journal of the Adventist Theological Society 10, no. 1/2 (1999).

${ }^{11}$ Fernando Canale, "Absolute Theological Truth in Postmodern Times", Andrews University Seminary Studies 45, no. 1 (2007).

${ }^{12}$ Como breve introducción a los efectos de la epistemología moderna en teología adventista lee, Fernando Canale, "From Vision to System: Finishing the Task of Adventist Theology Part 1: Historical Review", Journal of the Adventist Theological Society 15, no. 2 (2004).

${ }^{13}$ Adventistas modernos son quienes siguen los ideales de la ciencia para interpretar la Escritura. El sello de su preferencia "Adventistas progresivos".

14 “la Biblia no está para ser puesta a prueba por las ideas de hombres de ciencia, pero la ciencia debe ser llevada a prueba ante la Norma Infalible. Cuando la Biblia hace afirmaciones de algún hecho en esencia, la ciencia debe ser comparada con la palabra escrita, y un correcto entendimiento de ambos siempre les probará estar en armonía. Una no contradice a la otra. Todas las verdades, sea en naturaleza o revelación, están siempre de acuerdo. La investigación científica abrirá en las mentes de los realmente sabios, amplios campos de pensar e información. Verán a Dios en su trabajo y lo alabarán. Él será el primero y mejor, y la mente se centrará en Él”. Ellen White, Healthful Living (Battle Creek, MI: Medical Missionary Board, 1898), 286-287.

${ }^{15}$ Ellen White, Counsels to Parents, Teachers, and Students. (Mountain View, CA: Pacific Press Publishing Association,, 1943). 425.

${ }^{16}$ Noah Webster's American Dictionary, 1828, in Ellen G. White Writings Complete Published Edition. The Ellen White Estate, Inc., www.WhiteEstate.org, 2007.

${ }^{17} \mathrm{lbid}$.

${ }^{18}$ La Ontología General estudia los fundamentos de la realidad como el concepto del "ser". Para ontólogos, "ser" es el concepto más general que incluye todo lo que la mente humana puede imaginar. En términos más simples podemos decir que la ontología estudia el significado de la palabra "es".

${ }^{19}$ Aun, estas disciplinas no existen. Para una introducción a la tarea futura, lee. Fernando Canale, "From Vision to System: Finishing the Task of Adventist Theology: Part 3 Sanctuary and Hermeneutics," Journal of the Adventist Theological Society 17, no. 2 (2006).

${ }^{20}$ En el campo de la teología, los eruditos asumen la interpretación eterna de Dios y la ontología humana derivada de la interpretación filosófi a griega y evolución como el principio cosmológico.

${ }^{21}$ Ellen White, Evangelism, (Washington, D.C.: Review and Herald Publishing Association, 1970): 589. 
